\title{
Tracking Cognitive Change over 24 Weeks with Longitudinal Functional Magnetic Resonance Imaging in Alzheimer's Disease
}

\author{
Donald G. McLaren ${ }^{a}$ b, e,f Aishwarya Sreenivasan ${ }^{a, e, f} \quad$ Eli L. Diamond ${ }^{a, b}$ \\ Meghan B. Mitchella, b, e,f Koene R.A. Van Dijk ${ }^{e, g}$ Amy N. DeLuca ${ }^{e}$ \\ Jacqueline L. O'Brien ${ }^{c, e}$ Dorene M. Rentz ${ }^{b, d}$, e Reisa A. Sperling ${ }^{a, b}$, d, e
}

Alireza Atria, $b, e, f$

a Department of Neurology, Massachusetts General Hospital, ${ }^{b}$ Harvard Medical School, ' Harvard School of Public Health, and d Center for Alzheimer Research and Treatment, Department of Neurology, Brigham and Women's Hospital, Boston, Mass., e Athinoula A. Martinos Center for Biomedical Imaging, Massachusetts General Hospital, Charlestown, Mass., ${ }^{\mathrm{f} G e r i a t r i c ~ R e s e a r c h, ~ E d u c a t i o n ~ a n d ~ C l i n i c a l ~ C e n t e r, ~ E N R M ~ V A ~ M e d i c a l ~ C e n t e r, ~ B e d f o r d, ~ M a s s ., ~}$ and ${ }^{9}$ Department of Psychology, Center for Brain Science, Harvard University, Cambridge, Mass., USA

\section{Key Words}

Functional MRI • Clinical trial • Episodic memory •

Biomarker · Dementia

\begin{abstract}
Background: Previous studies have revealed that functional magnetic resonance imaging (fMRI) blood oxygen level-dependent (BOLD) signal in specific brain regions correlates with cross-sectional performance on standardized clinical trial measures in Alzheimer's disease (AD); however, the relationship between longitudinal change in fMRI-BOLD signal and neuropsychological performance remains unknown. Objective: To identify changes in regional fMRI-BOLD activity that tracks change in neuropsychological performance in mild AD dementia over 6 months. Methods: Twenty-four subjects (mean age 71.6) with mild AD dementia (mean Mini Mental State Examination 21.7, Global Clinical Dementia Rating 1.0) on stable donepezil dosing participated in two task-related $\mathrm{fMRI}$ sessions consisting of a face-name paired associative encoding memory paradigm 24 weeks apart during a randomized placebo-controlled pharmaco-fMRI drug
\end{abstract}

\section{KARGER \\ Fax +4161306 1234 \\ E-Mail karger@karger.ch}

www.karger.com
(C) 2012 S. Karger AG, Basel

$1660-2854 / 12 / 0094-0176 \$ 38.00 / 0$

Accessible online at:

www.karger.com/ndd study. Regression analysis was used to identify regions where the change in $\mathrm{fMRI}$ activity for Novel $>$ Repeated stimulus contrast was associated with the change scores on postscan memory tests and the Free and Cued Selective Reminding Test (FCSRT). Results: Correlations between changes in postscan memory accuracy and changes in fMRI activity were observed in regions including the angular gyrus, parahippocampal gyrus, inferior frontal gyrus and cerebellum. Correlations between changes in FCSRT-free recall and changes in $\mathrm{FMRI}$ were observed in regions including the inferior parietal lobule, precuneus, hippocampus and parahippocampal gyrus. Conclusion: Changes in encoding-related fMRI activity in regions implicated in mnemonic networks correlated with changes in psychometric measures of episodic memory retrieval performed outside the scanner. These exploratory results support the potential of fMRI activity to track cognitive change and detect signals of short-term pharmacologic effect in early-phase AD studies.

Copyright $\odot 2012$ S. Karger AG, Basel

D.G.M. and A.S. contributed equally to the present work.
Alireza Atri, MD, PhD

MGH Memory Disorders Unit

15 Parkman Street, WACC 715

Boston, MA 02114 (USA)

Tel. +1 617726 1728, E-Mail atri@nmr.mgh.harvard.edu 


\section{Introduction}

With promising therapies for Alzheimer's disease (AD) entering clinical trials, functional magnetic resonance imaging (fMRI) has potential as a complementary biomarker to provide an early signal of effect or efficacy, particularly in early-phase proof-of-concept human studies[1, 2]. Group level differences in regionally specific fMRI activity associated with aging, mild cognitive impairment, $\mathrm{AD}$, and memory-affecting drugs have been observed [3-11]. We previously reported that regionally specific fMRI-blood oxygen level-dependent (BOLD) signal, an indirect measure of neuronal activity during paired-associate encoding, correlates with performance on memory measures performed outside the scanner [12]. In the present study, we used the same fMRI task and memory measures to explore potential longitudinal relationships between regional task-related fMRI activity and performance on memory tests. We hypothesized that changes in performance on memory measures would be correlated with changes in fMRI activity in brain regions involved in encoding and associative memory (e.g., hippocampus, default-mode network regions), especially in areas we previously observed to have cross-sectional correlated activity with clinical-trial memory measures [12].

\section{Methods}

\section{Subjects}

Twenty-four right-handed, English-speaking subjects meeting the National Institute of Neurological Disorders and Stroke (NINCDS)/Alzheimer's Disease and Related Disorders Association (ADRDA) criteria for Probable AD [13], with Mini-Mental State Examination (MMSE) scores between 16 and 24, and on stable-dose donepezil (Aricept ${ }^{\circledR}$ ) $10 \mathrm{mg}$ daily for $>6$ months were enrolled in the study (table 1). In specialty memory clinics, use of the NINCDS/ADRDA criteria for Probable AD has demonstrated approximately 90-95\% diagnostic accuracy for AD [14]. In the present study, the subjects were first diagnosed clinically with AD by a clinical neurologist, were then evaluated at one of two University Memory Disorders Units and given the clinical diagnosis of probable AD by a cognitive neurologist, a diagnosis which was then reviewed and confirmed by the memory disorders unit's consensus committee. As part of this study, a cognitive neurologist (A.A.) and a senior neuropsychologist (D.M.R.) both evaluated each subject based on standard NINCDS/ADRDA criteria, and along with clinical judgment, additional collateral input from a knowledgeable and reliable study partner, cognitive testing (including the MMSE) and measures (including the clinical dementia rating scale), review of brain MRI, clinical records and tests, agreed on the research diagnosis of probable $\mathrm{AD}$ [15]. Using these procedures, and due to longitudinal follow-up, the likelihood of misdiagnosis for dementia is zero: all patients were demented at the time of the study and continued to decline thereafter. The likelihood of neurodegenerative disease other than AD being primarily causative of dementia in these particular subjects, though not zero, is very low, and is probably much less than 5\%. Exclusion criteria included unstable psychiatric or medical illness, severe renal insufficiency, contraindication to MRI, and use of antipsychotic medication in the 6 months prior to screening. Subjects and caregivers provided informed consent in accordance with protocols approved by the Partners Healthcare Inc. Institutional Review Board.

\section{Study Procedure}

Subjects underwent baseline fMRI and cognitive testing, and were randomized in a 1:1 ratio: one half received memantine (Namenda) that was titrated over 3 weeks to $10 \mathrm{mg}$ twice daily, and the remainder received twice daily placebo. After 12 weeks, the subjects on placebo were switched to memantine. After 24 weeks, the subjects underwent fMRI and cognitive testing again. Neuropsychological and clinical measures included: MMSE [16], Alzheimer's Disease Assessment Scale - Cognitive Subscale (ADAS-Cog) [17], Free and Cued Selective Reminding Test (FCSRT) [18], and Clinical Dementia Rating Scale (CDR) [19].

The ADAS-Cog, MMSE and CDR are commonly used in AD clinical trials. The FCSRT measures controlled associative learning and has high sensitivity for early dementia $[18,20]$. The subjects first name each of four pictured items (e.g. grapes, tiger) that go with a unique category cue (e.g. fruit, animal). After all four items are identified, immediate cued recall of just those four items is tested. After controlled learning is completed for 16 items in four categories, there are three test trials consisting of free recall, followed by selective cued reminding for items not retrieved earlier in the trial. The sum of freely recalled words is the free-recall score (FCSRT-free) and the sum of items recalled across all conditions is the total-recall score (FCSRT-total); scores for both range from 0 to 48 .

\section{MRI Protocol}

Functional MRI Acquisition

A General Electric 3.0-tesla Signa (Waukesha, Wisc., USA) MRI system with a quadrature birdcage head coil was utilized. High-resolution $\mathrm{T}_{1}$-weighted structural imaging utilized a spoiled gradient recalled sequence with repetition time $(\mathrm{TR})=$ $7.25 \mathrm{~ms}$, echo time $(\mathrm{TE})=3 \mathrm{~ms}$, field of view $(\mathrm{FOV})=240 \times 240$ $\mathrm{mm}$, flip angle $(\mathrm{FA})=7^{\circ}$, matrix $=256 \times 256 \mathrm{~mm}$, and $128 \mathrm{sag}$ ittal slices with a thickness of $1.33 \mathrm{~mm}$. Functional scans utilized $\mathrm{a} \mathrm{T}_{2}{ }^{*}$-weighted gradient-echo echo-planar image (EPI) BOLD sequence with $\mathrm{TR} / \mathrm{TE}=2,500 / 30 \mathrm{~ms}, \mathrm{FOV}=240 \times 240 \mathrm{~mm}, \mathrm{FA}=$ $90^{\circ}$, matrix $=64 \times 64$, and 29 oblique coronal slices with a thickness of $5 \mathrm{~mm}$ perpendicular to the AC-PC line with a 1-mm gap. Functional scans consisted of 6 task runs, each having 102 time points.

\section{Task Design}

The same block design face-name associative encoding fMRI paradigm as that used by Diamond et al. was employed [12]. This task was chosen based on its extensive use over the past decade in probing the functional neuroanatomical specificity of associative memory encoding processes $[1,3,4,10,12,21-25]$. The face- 
Table 1. Demographics and cognitive tests

\begin{tabular}{|c|c|c|c|c|c|}
\hline \multirow[t]{2}{*}{ Demographics } & Age, years & $71.63 \pm 1.71$ & & & \\
\hline & Gender $(\mathrm{f} / \mathrm{m})$ & $9 / 15$ & & & \\
\hline \multirow[t]{8}{*}{ Cognitive tests } & $\mathrm{FR}, \%$ correct & $67.00(3.05)^{1}$ & $60.10(2.57)$ & $-6.91(2.89)$ & 0.025 \\
\hline & FCR, \% correct & $68.75(3.31)^{1}$ & $61.50(2.79)$ & $-7.25(3.11)$ & 0.029 \\
\hline & ADAS-Cog Total, number of errors & $26.15(1.90)^{3}$ & $28.13(2.19)$ & $1.98(1.16)$ & 0.100 \\
\hline & ADAS-Cog Recall, number of errors & $5.94(0.35)^{3}$ & $6.21(0.38)$ & $0.28(0.21)$ & 0.198 \\
\hline & ADAS-Cog Delayed Recall, number of errors & $8.33(0.39)^{3}$ & $8.83(0.44)$ & $0.50(0.26)$ & 0.070 \\
\hline & ADAS-Cog Recognition, number of errors & $6.71(0.66)^{3}$ & $7.13(0.74)$ & $0.42(0.81)$ & 0.614 \\
\hline & MMSE, number correct & $24.04(0.58)^{2}$ & $23.17(0.72)$ & $-0.88(0.50)$ & 0.094 \\
\hline & CDR-SB, score & $4.67(0.50)^{4}$ & $4.75(0.60)$ & $0.08(0.23)$ & 0.721 \\
\hline
\end{tabular}

CDR-SB = CDR sum of boxes. For FCSRT, MMSE and postscan memory tests, higher scores indicate better performance. For CDRsum of boxes and ADAS-Cog, lower scores represent better performance. ${ }^{*}$ p values do not account for multiple comparisons - doing so, none of the above $\mathrm{p}$ values are $\leq 0.05 .{ }^{1}$ Figures in parentheses represent mean (SD) of percentage of correct answers. ${ }^{2}$ Figures in parentheses represent mean (SD) of number of correct answers. ${ }^{3}$ Figures in parentheses represent mean (SD) of percentage of errors. ${ }^{4}$ Figures in parentheses represent mean (SD) of CDR-SB score.

name paradigm is also highly clinically relevant; it is a crossmodal associative memory paradigm that compares the encoding of novel face-name pairs to viewing highly familiarized repeated face-name pairs, as difficulty remembering proper names remains the most common complaint of older individuals [26]. The task consists of three conditions presented in blocks: (1) novel face-name pairs, in which unfamiliar faces are paired with first names each shown once (5-second duration); (2) repeated face-name pairs, in which two face-name pairs are repeatedly alternated during each block, and (3) fixation cross. Subjects are instructed to press a button to indicate whether or not a name fits a face and to remember the pair. A total of 84 novel face-name pairs and 2 repeated face-name pairs were used. After scanning, subjects were asked to freely recall names for faces they recognized as being presented (FR) and were next asked to identify the correct name for faces in a forced-choice recognition (FCR) format. To avoid learning effects, the novel face-name pairs and repeated face-name pairs used at baseline and at week 24 were different. Previous work from our group has shown high reliability between scans in healthy young adults, healthy elderly participants, individuals with mild cognitive impairment, and in $\mathrm{AD}$ patients [10, 24, 27]. As reported in Putcha et al. [24], we found no associations between change in postscan memory performance and change in BOLD activity in older normal controls (CDR 0) and subjects with mild cognitive impairment (CDR 0.5).

\section{Image Preprocessing and First-Level Analyses}

Images were slice time corrected using Analysis of Functional Neuroimages (AFNI; Medical College of Wisconsin, Wisc., USA). Then the following preprocessing steps were completed in Statistical Parametric Mapping software (SPM8; Wellcome Department of Imaging Neuroscience, University College London, UK):
(1) motion corrected; (2) spatially normalized to the Montreal Neurological Institute EPI template image; (3) resampled to 2-mm isotropic voxels, and (4) smoothed with an $8-\mathrm{mm}$ full width at half maximum (FWHM) Gaussian kernel. General linear models were used to derive single subject activations for the novel encoding and repeated encoding blocks (see online suppl. material: 'First-level General Linear Model (GLM)'; for all online suppl. material, see www.karger.com/doi/10.1159/000335876).

\section{Second-Level Analysis: Correlation between Change in $f M R I$} and Change in Clinical and Cognitive Measures

Whole-brain linear regression investigated which regions showed a correlation between changes in fMRI signal and in behavioral performance over time. The difference between the Novel $>$ Repeated stimulus contrast $(\mathrm{N}>\mathrm{R})$ at baseline and 24 weeks was entered into the models as the dependent variable. Separate models used change scores from baseline to 24 weeks for MMSE, ADAS-Cog Total, ADAS-Cog Recognition, FCSRT-free, FCSRT-total, FR and FCR as independent variables. Models also included a group term. Significant clusters were defined where there were at least 50 contiguous voxels $\left(400 \mathrm{~mm}^{3}\right)$ attaining $\mathrm{p}<$ 0.005 .

\section{Results}

\section{Clinical Performance}

Table 1 summarizes clinical performance at baseline and week 24 for all subjects $(\mathrm{n}=24)$. There were no significant differences on performance for any cognitive or clinical test measure between baseline and week 24 (at 


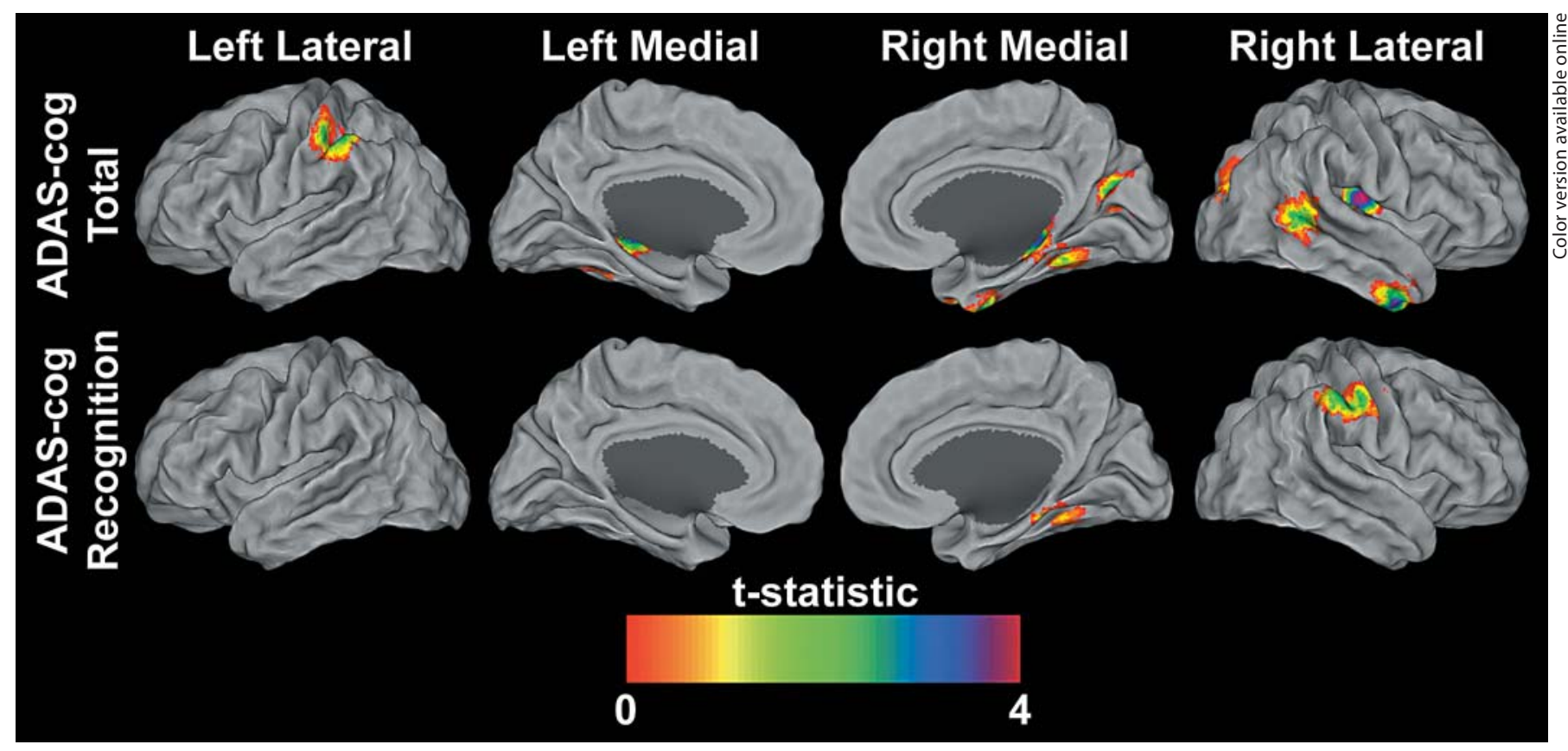

Fig. 1. Statistical parametric maps at $p<0.005$ and extent of 50 contiguous voxels of ADAS-Cog-negative correlations with fMRI. The results are projected onto the PALS surface in Caret $[66,67]$ using the multifiducial mapping approach. To aid in the visualization of the hippocampus, the maximal voxel within a 5-mm-cube of each node was selected. These surface maps represent both the spatial variability and the magnitude of the significant correlations.

$\mathrm{p}=0.05$ adjusting for multiple comparisons). Also, subgroup analysis (not shown) comparing the subgroups of subjects initially randomized to placebo versus randomized to the study drug, memantine, did not reveal any significant differences within or between subgroups at either baseline or at week 24 , nor any significant changes between subgroups from baseline to week 24; a future study will assess potential drug-related effects on fMRIbehavioral signals.

Correlation between Change in Clinical Measures and Change in $F M R I-B O L D$ Signal

\section{ADAS-Cog Total Errors}

Regression analysis identified regions where changes in $\mathrm{N}>\mathrm{R}$ contrasts were significantly associated with changes in ADAS-Cog total errors (online suppl. table S1). Change scores for ADAS-Cog total errors negatively correlated with fMRI-BOLD signal changes in the left and right hippocampus, right superior occipital gyrus, right insula, left and right cerebellum, right middle temporal gyrus and right inferior temporal gyrus (fig. 1). Thus, more errors at follow-up as compared to baseline were associated with less change or a decrease in fMRI signal over time. No regions were found showing a positive relationship between ADAS-Cog total errors and $\mathrm{N}>\mathrm{R}$ changes.

\section{ADAS-Cog Recognition Errors}

Regression analysis identified regions where changes in $\mathrm{N}>\mathrm{R}$ contrasts were significantly associated with changes in ADAS-Cog recognition errors (online table S2). Change scores for ADAS-Cog recognition errors negatively correlated with $\mathrm{AMRI-BOLD}$ signal changes in the left inferior parietal lobule, right supramarginal gyrus and the right cerebellum (fig. 1). No regions were found showing a positive relationship between ADASCog recognition errors and $\mathrm{N}>\mathrm{R}$ changes.

\section{FCSRT-Free Recall}

Regression analysis identified regions where changes in $\mathrm{N}>\mathrm{R}$ contrasts were significantly associated with changes in FCSRT-free recall (online table S3). Change scores for FCSRT-free recall were positively correlated with $\mathrm{fMRI}$-BOLD signal changes in regions that included pre- and postcentral gyri, inferior parietal lobule, left precuneus, right middle frontal gyrus, right middle cingu- 


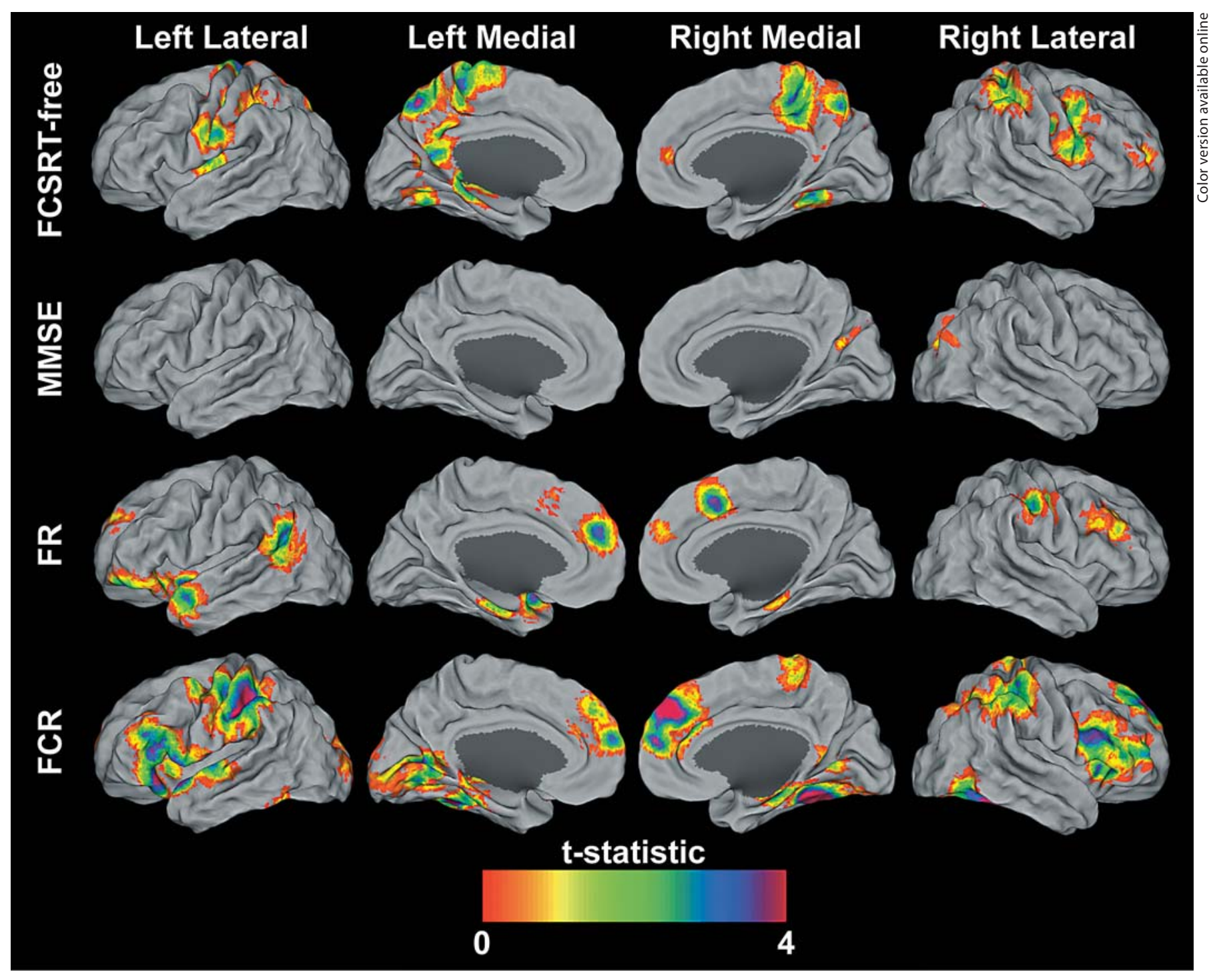

Fig. 2. Statistical parametric maps at $\mathrm{p}<0.005$ and extent of 50 contiguous voxels of MMSE, FCSRT-free, FR, and FCR positive correlations with fMRI. The results are projected onto the PALS surface in Caret $[66,67]$ using the multifiducial mapping approach. To aid in the visualization of the hippocampus, the maximal voxel within a $5-\mathrm{mm}$ cube of each node was selected. These surface maps represent both the spatial variability and the magnitude of the significant correlations.

late gyrus, paracentral lobule, left posterior cingulate, fusiform gyrus, and left hippocampus and parahippocampus (fig. 2). No regions were found showing a negative relationship between FCSRT-free recall and N $>$ R changes.

\section{Mini-Mental State Examination}

Regression analysis identified regions where changes in $\mathrm{N}>\mathrm{R}$ contrasts were significantly associated with changes in MMSE (online table S4). Change scores for MMSE were positively correlated with fMRI-BOLD signal changes in the right middle occipital lobe (fig. 2). The lack of average change in MMSE over time means that some individuals showed improved scores over time and increased fMRI signal over time, while others show a decline in scores over time and a decreased fMRI signal over time. No regions were found showing a negative relationship between MMSE and N $>$ R changes. 


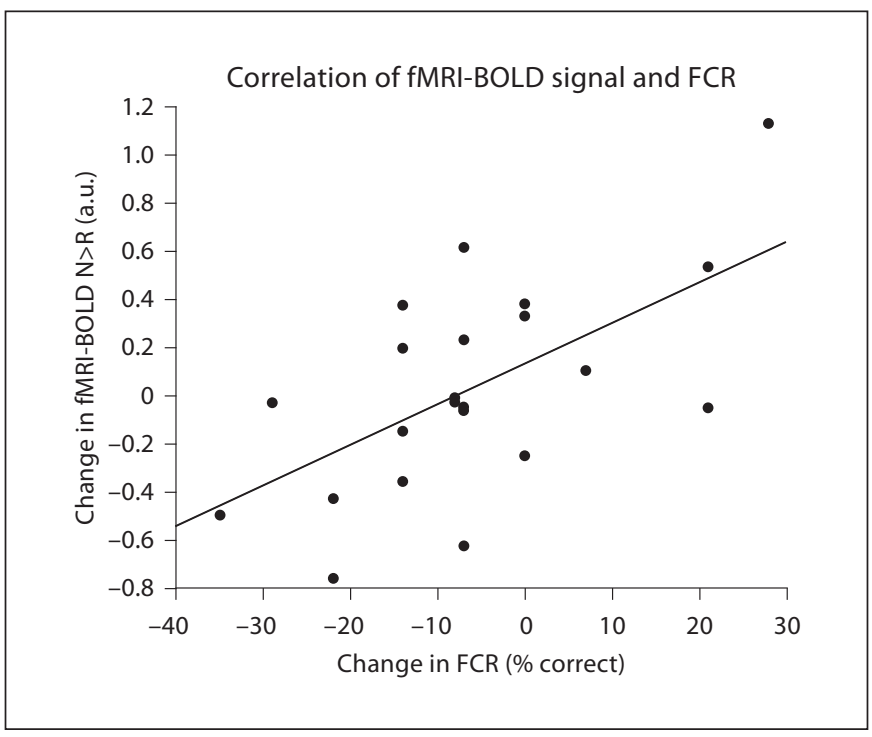

Fig. 3. Correlation between the change in FCR and the change in the $\mathrm{N}>\mathrm{R}$ fMRI-BOLD signal in the right hippocampus.

Free Recall

Regression analysis identified regions where changes in $\mathrm{N}>\mathrm{R}$ contrasts were significantly associated with changes in FR (online table S5). Change scores for FR were positively correlated with fMRI-BOLD signal changes in a number of regions including the left angular gyrus, right middle temporal gyrus, brainstem, left parahippocampal gyrus, right cerebellum, left inferior frontal gyrus, right precentral gyrus, right supplemental motor area, middle frontal gyrus, and left superior middle frontal gyrus (fig. 2). No regions were found showing a negative relationship between FR and $\mathrm{N}>\mathrm{R}$ changes.

\section{Forced-Choice Recognition}

Regression analysis identified regions where changes in $\mathrm{N}>\mathrm{R}$ contrasts were significantly associated with changes in FCR (online table S6, fig. 3). Change scores for FCR were positively correlated with fMRI-BOLD signal changes in a number of regions including the cerebellum, fusiform gyrus, right brainstem, inferior temporal gyrus, right inferior occipital lobe, left calcarine sulcus, left lingual gyrus, inferior frontal gyrus pars triangularis, left inferior parietal lobule, left pre- and post-central gyrus, right hippocampus, left and right medial superior frontal gyrus, and right middle frontal gyrus (fig. 2). No regions were found showing a negative relationship between FCR and $\mathrm{N}>\mathrm{R}$ changes.

Association of Longitudinal fMRI and

Neuropsychological Change in AD

\section{Discussion}

While much is known about structural MRI correlates of longitudinal memory performance in AD [28-33], analogous fMRI correlates are poorly delineated. This study explores the hypothesis that, in subjects with mild $\mathrm{AD}$, candidate brain regions supporting associativememory processes may be identified in which changes in encoding-related fMRI activity over 24 weeks vary with changes in performance on behavioral tests and clinicaltrial memory measures. The rationale underlying this hypothesis is that individuals who show increased brain modulation during the memory task at follow-up show better performance at follow-up and individuals who show decreased brain modulation during the memory task at follow-up may also show worse task performance at follow-up. Using whole-brain statistical parametric maps, changes in fMRI activity during encoding of facename pairs for a group of 22 subjects with mild AD significantly correlated with changes in ADAS-Cog total and word recognition, FCSRT-free, MMSE, and postscan name recall and postscan forced-choice name recognition for faces in several brain areas. These areas included parietal, medial temporal lobe (MTL) and frontal regions linked to retrieval of episodic memory and attentional control; these areas all undergo early structural changes in $\mathrm{AD}$. The results presented here extend findings from cross-sectional clinical and cognitive studies [12] to identify candidate functional measures that may provide additional support in proof-of-concept human clinical trials to gauge effects for promising $\mathrm{AD}$ drugs.

This study design and implementation have several important strengths that make results relevant to earlyphase clinical researchers. These are inclusion of wellcharacterized mild-AD subjects with clinical, demographic and medication usage profiles typical of AD clinical-trial populations, administration of several standard clinical and neuropsychological measures commonly used in AD clinical trials, application of a well-characterized and robust fMRI associative-encoding paradigm, implementation of fMRI within the structure of a shortterm, 24-week, randomized, controlled, blinded, AD clinical-trial format similar to phase 2 studies of symptomatic efficacy in $\mathrm{AD}$, achievement of high subject follow-up and data integrity, and utilization of standard and widely available MRI processing and analysis streams and software. Important to the feasibility of using cognitive tests and fMRI as reliable measures in clinical trials is that there be no learning effect over time. The present paradigm has been shown to have high reliability across 
time and the stimuli used at baseline and the week- 24 visits were different $[1,10,24]$. Additionally, the neuropsychological measures utilized in this study have both high validity and reliability across time in mild AD dementia $[20,34,35]$.

The relationships between performance changes and fMRI changes in brain regions reported here are also supported by previous work that implicates these regions as supporting aspects of visual and verbal memory-related processes, as well as data from our previous study that examined a cross-sectional behavioral-fMRI link using the same paradigm [12]. In that study, the $\mathrm{N}>\mathrm{R}$ contrast was correlated with ADAS-Cog scores, postscan memory performance, MMSE and FCSRT scores.

\section{Effects Related to FCSRT-Free Recall Change Scores}

Activity changes in the left inferior parietal and left precuneus correlated significantly with changes in performance on FCSRT-free recall. Inferior parietal regions are associated with correctly recalled items during cued recall [36]. The left inferior parietal cortex, in particular, is involved in procedural and declarative memory processes [37, 38] and encoding of unfamiliar faces [39] conditions akin to encoding of novel name-face pairs in this fMRI paradigm.

Episodic retrieval has been implicated in the activity of the lateral posterior parietal cortex and the precuneus [40-42], which are important components of the default mode network (DMN) [43-48]. The DMN is characteristically active during task-independent, introspective thought processes, and its function may be particularly affected in cognitive aging and disrupted in patients with mild cognitive impairment and AD [5, 43, 46, 49]. The precuneus, considered a major hub in the $\mathrm{DMN}$, is also strongly connected with the inferior and superior parietal lobules [50] and is important for successful encoding [4].

The regional investigation of activity in the DMN yields further insight into how the DMN is affected by $\mathrm{AD}[3,25,51,52]$. Over the 24 -week trial window, activity related to novel face-name encoding increased in all regions and groups; whether and how such an increase may represent a signal of potential drug effect requires additional studies. Future analyses will investigate how the DMN and other intrinsic brain network patterns change over time and address associations with potential signals of antidementia drug effects.

\section{Effects Related to ADAS-Cog Change Scores}

Changes in activation were observed in frontal and parietal regions, including the inferior parietal cortex and middle temporal gyrus that significantly correlated with ADAS-Cog change scores. Lateral and inferior parietal regions are implicated in several memory processes including in old/new recognition [53] and in visual recognition of words [54].

\section{Effects Related to FR and FCR Change Scores}

Changes in activation that significantly correlated with postscan memory test scores were observed in frontal, temporal and parietal regions, including the inferior frontal gyrus, middle temporal gyrus and inferior parietal cortex; regions that may serve as hubs in important cognitive networks, including the DMN [43, 45, 55-57], in the perceptual decision-making circuit, and in attentional control [58]. The findings of significant correlations between changes in memory tests outside the scanner with changes in magnitude of encoding-related activity inside the scanner for MTL structures supports the utility of this block design, paired-associate, encoding paradigm for detecting and potentially tracking fMRI signal changes even in AD patients with significant MTL atrophy.

\section{Summary of Effects Related to Cognitive Test Score} Changes and Candidate Brain Regions

These results support activity changes in several regions previously implicated in cross-sectional studies to have encoding-related activity associated with memory performance outside the scanner (e.g. inferior parietal lobule, superior temporal gyrus, precuneus). However, we did not find extensive similar associations with more general measures of cognition that have low memory load (e.g. MMSE) $[12,59]$. Other than a true lack of association, other plausible explanations for these null results are that such global measures may have relatively smaller memory-related signals that would be otherwise detectable in isolation (e.g. via ADAS-Cog recognition) and in higher-powered studies, and that may be obfuscated in the context of a multidomain cognitive scale (i.e. ADASCog total). Also, associations for encoding-related fMRI activity with FCSRT-free and FCR may have been more readily detected since a greater range in performance was observed on these tests compared to the other memory tests.

The present study focused on probing the functional neuroanatomical specificity of memory changes in mild $\mathrm{AD}$, that generally occur earlier in the disease process relative to semantic cognition, apraxia and aphasia [60], rather than probing more general changes in cognition. As such, paradigms that strongly recruit memory-sensitive 
regions to complete the task will yield the best results. In comparison, tasks probing motor function, such as studies of swallowing in $\mathrm{AD}[61,62]$, are likely to be better suited than the present study to investigate functional neuroanatomical specificity for apraxia. Likewise, language tasks would be better suited than the present task for probing the functional neuroanatomical specificity of aphasia in neurodegenerative diseases and $\mathrm{AD}$ [63]. Uncovering the functional neuroanatomical specificity of cognitive changes in $\mathrm{AD}$ requires varied studies that probe different cognitive systems at different stages of the disease. Here we make a start by probing the longitudinal functional neuroanatomy of a brain system that supports encoding of highly ecologically important explicit associations, those of faces and names, and one that this is also a relatively early casualty of the destruction wrought by AD.

Identification of candidate brain regions that track cognitive performance provides researchers with locations to inspect for functional changes in early-phase or proof-ofconcept clinical trials; these regions could be monitored to assess for signals of drug effect and to track such effects over time. Ultimately, this information may be combined in integrative models with other biomarker data to better inform go-no go decisions for experimental drugs or doseresponse relationships, to elucidate early trends in efficacy, or to predict individual treatment responses.

The utilization of imaging biomarkers is not a replacement for neuropsychological testing, but rather a complement to them. If the correlation between imaging and behavior were 1 , then there would not be a need for imaging biomarkers; however, this is not the case in the present results. High correlations provide evidence that we are capturing variance related to changes in memory performance, but also provide evidence that imaging biomarkers may have unique variance that could be leveraged in early-phase trials. Thus, the goal is not to replace neuropsychological tests, but to develop imaging biomarkers that, when combined in integrated models with other variables (including neuropsychological measures), yield greater explanatory power, particularly for clinical changes over time. In particular, fMRI potentially manifests signals of effects at the synaptic/local field potential levels, and these signals are likely to be detectable much earlier than changes in behavior in order to guide drug discovery, selection and therapeutic trial efforts. While the current results do not support accuracy at the level of the individual, they are nonetheless encouraging as they support the detection of a potential signal at the group level with N's that are modest enough to support their investigation in small early-phase/proof-of-concept AD trials [1,24].
The main limitations of this study and the caveats in the results are as follows: First, there is an implicit assumption that chronic administration of antidementia medications does not significantly alter the function-behavioral performance relationship of the network(s) utilized during the encoding task. In other words, there is an invariance in the nature, not necessarily of the degree of any fMRI signal modulation when, as in this analysis, the aim is to assess whether fMRI activity may track clinical and cognitive measures, and to delineate regions where such changes may occur (i.e. that chronically stable antidementia drugs between week $0 / 12$ and 24 do not fundamentally alter the shared regions involved in the networks supporting these tasks). Second, in the present analysis, we do not study the potential modulatory effects of memantine on fMRI-BOLD signal or on function-behavioral performance relationships because effect sizes on cognitive measures in mild AD are unlikely to be detectable in short time frames and with only 24 subjects $[64,65]$ using such analysis - and in fact, as would be expected, the clinical measures did not show significant differences attributable to drug over the 24-week course of this study (i.e. accounting for multiple comparisons, there were no behavioral differences between the group that was on drug for 12 weeks and the group that was on drug for 24 weeks). Also, the relative homogeneity of our subjects and methods (e.g. single-site study, well-characterized subjects with high education, excellent adherence to protocol and follow-up) yields high internal reliability but may potentially limit generalizability to multisite studies. Finally, these results should be viewed as preliminary and will require replication in larger confirmatory studies, especially to assess whether performance changes on more global measures of cognition correlate with regional fMRI signals and whether the results are generalizable.

In conclusion, these results suggest that functional changes in several MTL and parietal brain regions may be potentially useful in tracking signals for change in memory performance over short periods in patients with mild AD. Our findings also provide further support for the potential of encoding task-fMRI as a complementary biomarker of $\mathrm{AD}$ that warrants further study, particularly in the context of early-phase clinical trials.

\section{Acknowledgements}

Funding/Support: the study was supported by: NIA National Institute on Aging grants K23 AG027171 (Dr. Atri) and RO1 AG027435 (Dr. Sperling); The Harvard-Massachusetts Institute 
of Technology Health Sciences \& Technology Pfizer-Merck Clinical Investigator Training Program (Dr. Atri); the NIH National Institutes of Health loan repayment program (Dr. Atri); Investigator-Initiated Research Grants from Forest Pharmaceuticals and The Harvard Center for Neurodegeneration \& Repair; the Clinical, Neuroimaging, and Statistics Cores of the Massachusetts Alzheimer's Disease Research Center (NIA National Institute on Aging grant P50 AG05134 to Drs. Growdon and Hyman); and the Geriatric Research, Education and Clinical Center (GRECC) at the Edith Nourse Rogers Memorial (ENRM) Veterans Administration (VA) Bedford Medical Center. Less than 30\% of this research was supported by an Investigator-Initiated Research Grant from Forest Research Institute. The contents of this study do not represent the views of the Department of Veterans Affairs or the United States Government.

Dr. Kim Celone, Mrs. Kristina DePeau, Mr. Peter LaViolette, Mr. Saul Miller, Ms. Kelly O’Keefe, Dr. Maija Pihlamajaki, Dr. Meghan Searl, Ms. Sarah Rastegar, and Ms. Sibyl Salisbury provided assistance with data collection or data processing. Dr. John Growdon (Massachusetts General Hospital Memory Disorders Unit \& Massachusetts Alzheimer's Disease Research Center) provided significant assistance with recruitment of participants, obtaining space, and resources, and guidance. Dr. Bruce Rosen
(MGH-Harvard-MIT Martinos Center for Biomedical Imaging) provided guidance, space, and resources for this research. Finally, and most importantly, we express our deep gratitude for the commitment of the patients, family members, and caregivers, without whose generous contribution and dedication this research would not have been possible.

\section{Disclosure Statement}

A.A., within the past 5 years, has served as a consultant, on the advisory board, received lecture honoraria, or institutional-research grant funding from Eisai Pharmaceuticals, Forest Pharmaceuticals Inc., H. Lundbeck A/S, Merck \& Co Inc., Merz Pharmaceuticals, and Novartis AG. R.A.S. has served as a consultant for Eisai Pharmaceuticals, Elan Corporation plc, Pfizer Inc., Bristol-Myers-Squibb, and Roche. She has received institutional research funding or served as a site investigator for Elan, Pfizer, Bristol-Myers-Squibb, and Forest Pharmaceuticals. Principal support for this research was provided by the NIH/NIA (K23, R01, P50 grant mechanisms). The principal author, A.A., retains full control of the data and publication rights.

\section{References}

1 Atri A, O’Brien JL, Sreenivasan A, Rastegar S, Salisbury S, Deluca AN, O'Keefe KM, Laviolette PS, Rentz DM, Locascio JJ, Sperling RA: Test-retest reliability of memory task functional magnetic resonance imaging in Alzheimer disease clinical trials. Arch Neurol 2011;68:599-606.

- 2 Sperling RA, Aisen PS, Beckett LA, Bennett DA, Craft S, Fagan AM, Iwatsubo T, Jack CR, Kaye J, Montine TJ, Park DC, Reiman EM, Rowe CC, Siemers E, Stern Y, Yaffe K, Carrillo MC, Thies B, Morrison-Bogorad M, Wagster MV, Phelps CH: Toward defining the preclinical stages of Alzheimer's disease: recommendations from the National Institute on Aging and the Alzheimer's Association workgroups on diagnostic guidelines for Alzheimer's disease. Alzheimers Dement 2011;7:280-292.

-3 Sperling RA, Bates JF, Chua EF, Cocchiarella AJ, Rentz DM, Rosen BR, Schacter DL, Albert MS: fMRI studies of associative encoding in young and elderly controls and mild Alzheimer's disease. J Neurol Neurosurg Psychiatry 2003;74:44-50.

-4 Celone KA, Calhoun VD, Dickerson BC, Atri A, Chua EF, Miller SL, DePeau K, Rentz DM, Selkoe DJ, Blacker D, Albert MS, Sperling RA: Alterations in memory networks in mild cognitive impairment and Alzheimer's disease: an independent component analysis. J Neurosci 2006;26:10222-10231.
5 Andrews-Hanna JR, Snyder AZ, Vincent JL, Lustig C, Head D, Raichle ME, Buckner RL: Disruption of large-scale brain systems in advanced aging. Neuron 2007;56:924-935.

-6 Small SA, Perera GM, DeLaPaz R, Mayeux R, Stern Y: Differential regional dysfunction of the hippocampal formation among elderly with memory decline and Alzheimer's disease. Ann Neurol 1999;45:466-472.

-7 Saykin AJ, Flashman LA, Frutiger SA, Johnson SC, Mamourian AC, Moritz CH, O'Jile JR, Riordan HJ, Santulli RB, Smith CA, Weaver JB: Neuroanatomic substrates of semantic memory impairment in Alzheimer's disease: Patterns of functional MRI activation. J Int Neuropsychol Soc 1999;5:377-392.

$\checkmark 8$ Grady CL, McIntosh AR, Beig S, Keightley ML, Burian H, Black SE: Evidence from functional neuroimaging of a compensatory prefrontal network in Alzheimer's disease. J Neurosci 2003;23:986-993.

$\checkmark 9$ Thoenissen D, Zilles K, Toni I: Differential involvement of parietal and precentral regions in movement preparation and motor intention. J Neurosci 2002;22:9024-9034.

10 Sperling R, Greve D, Dale A, Killiany R, Holmes J, Rosas HD, Cocchiarella A, Firth P, Rosen B, Lake S, Lange N, Routledge C, Albert M: Functional MRI detection of pharmacologically induced memory impairment. Proc Natl Acad Sci USA 2002;99:455460.
11 Goekoop R, Scheltens P, Barkhof F, Rombouts SA: Cholinergic challenge in Alzheimer patients and mild cognitive impairment differentially affects hippocampal activation - a pharmacological fMRI study. Brain 2006;129:141-157.

12 Diamond EL, Miller S, Dickerson BC, Atri A, DePeau K, Fenstermacher E, Pihlajamaki M, Celone K, Salisbury S, Gregas M, Rentz D, Sperling RA: Relationship of fMRI activation to clinical trial memory measures in Alzheimer disease. Neurology 2007;69: 1331-1341.

13 McKhann G, Drachman D, Folstein M, Katzman R, Price D, Stadlan EM: Clinical diagnosis of Alzheimer's disease: Report of the NINCDS-ADRDA work group under the auspices of Department of Health and Human Services task force on Alzheimer's disease. Neurology 1984;34:939-944.

-14 Burns A, Luthert P, Levy R, Jacoby R, Lantos $\mathrm{P}$ : Accuracy of clinical diagnosis of Alzheimer's disease. BMJ 1990;301:1026.

15 McKhann GM, Knopman DS, Chertkow H, Hyman BT, Jack CR, Jr., Kawas CH, Klunk WE, Koroshetz WJ, Manly JJ, Mayeux R, Mohs RC, Morris JC, Rossor MN, Scheltens P, Carrillo MC, Thies B, Weintraub S, Phelps $\mathrm{CH}$ : The diagnosis of dementia due to Alzheimer's disease: recommendations from the National Institute on Aging-Alzheimer's Association workgroups on diagnostic guidelines for Alzheimer's disease. Alzheimers Dement 2011;7:263-269. 
$\checkmark 16$ Folstein MF, Robins LN, Helzer JE: The Mini-Mental State Examination. Arch Gen Psychiatry 1983;40:812.

17 Pena-Casanova J: Alzheimer's Disease Assessment Scale-Cognitive in clinical practice. Int Psychogeriatr 1997;9(suppl 1):105114.

-18 Grober E, Lipton RB, Hall C, Crystal H: Memory impairment on free and cued selective reminding predicts dementia. Neurology $2000 ; 54: 827-832$.

19 Morris JC: The clinical dementia rating (CDR): current version and scoring rules. Neurology 1993;43:2412-2414.

20 Grober E, Sanders AE, Hall C, Lipton RB: Free and cued selective reminding identifies very mild dementia in primary care. Alzheimer Dis Assoc Disord 2010;24:284-290.

- 21 Sperling RA, Bates JF, Cocchiarella AJ, Schacter DL, Rosen BR, Albert MS: Encoding novel face-name associations: a functional MRI study. Hum Brain Mapp 2001;14: 129-139.

-22 Sperling R, Chua E, Cocchiarella A, RandGiovannetti E, Poldrack R, Schacter DL, Albert M: Putting names to faces: successful encoding of associative memories activates the anterior hippocampal formation. Neuroimage 2003;20:1400-1410.

-23 Sperling R: Functional MRI studies of associative encoding in normal aging, mild cognitive impairment, and Alzheimer's disease. Ann N Y Acad Sci 2007;1097:146-155.

-24 Putcha D, O'Keefe K, Laviolette P, O’Brien J, Greve D, Rentz DM, Locascio J, Atri A, Sperling R: Reliability of functional magnetic resonance imaging associative encoding memory paradigms in non-demented elderly adults. Hum Brain Mapp 2011;32:20272044.

-25 Pihlajamaki M, Sperling RA: Functional MRI assessment of task-induced deactivation of the default mode network in Alzheimer's disease and at-risk older individuals. Behav Neurol 2009;21:77-91.

-26 Zelinski EM, Gilewski MJ: Assessment of memory complaints by rating scales and questionnaires. Psychopharmacol Bull 1988; 24:523-529.

-27 Atri A, O’Brien JL, Sreenivasan A, Rastegar S, Salisbury S, DeLuca AN, O'Keefe KM, LaViolette PS, Rentz DM, Locascio JJ, Sperling RA: Test-retest reliability of memory task fMRI in Alzheimer's disease clinical trials. Arch Neurol 2011;68:599-606.

-28 Apostolova LG, Hwang KS, Andrawis JP, Green AE, Babakchanian S, Morra JH, Cummings JL, Toga AW, Trojanowski JQ, Shaw LM, Jack CR Jr, Petersen RC, Aisen PS, Jagust WJ, Koeppe RA, Mathis CA, Weiner MW, Thompson PM: 3D PIB and CSF biomarker associations with hippocampal atrophy in ADNI subjects. Neurobiol Aging 2010;31 $1284-1303$.
29 Dickerson BC, Stoub TR, Shah RC, Sperling RA, Killiany RJ, Albert MS, Hyman BT, Blacker D, Detoledo-Morrell L: Alzheimersignature MRI biomarker predicts $\mathrm{AD}$ dementia in cognitively normal adults. Neurology 2011;76:1395-1402.

- 30 Dickerson BC, Bakkour A, Salat DH, Feczko E, Pacheco J, Greve DN, Grodstein F, Wright CI, Blacker D, Rosas HD, Sperling RA, Atri A, Growdon JH, Hyman BT, Morris JC, Fischl B, Buckner RL: The cortical signature of Alzheimer's disease: Regionally specific cortical thinning relates to symptom severity in very mild to mild $A D$ dementia and is detectable in asymptomatic amyloid-positive individuals. Cereb Cortex 2009;19:497-510.

- 31 Jack CR Jr, Wiste HJ, Vemuri P, Weigand SD, Senjem ML, Zeng G, Bernstein MA, Gunter JL, Pankratz VS, Aisen PS, Weiner MW, Petersen RC, Shaw LM, Trojanowski JQ, Knopman DS: Brain $\beta$-amyloid measures and magnetic resonance imaging atrophy both predict time-to-progression from mild cognitive impairment to Alzheimer's disease. Brain 2010;133:3336-3348.

32 Deweer B, Lehericy S, Pillon B, Baulac M, Chiras J, Marsault C, Agid Y, Dubois B: Memory disorders in probable Alzheimer's disease: the role of hippocampal atrophy as shown with MRI. J Neurol Neurosurg Psychiatry 1995;58:590-597.

33 de Toledo-Morrell L, Dickerson B, Sullivan MP, Spanovic C, Wilson R, Bennett DA: Hemispheric differences in hippocampal volume predict verbal and spatial memory performance in patients with Alzheimer's disease. Hippocampus 2000;10:136-142.

34 Fillenbaum GG, Heyman A, Wilkinson WE, Haynes CS: Comparison of two screening tests in Alzheimer's disease. The correlation and reliability of the Mini-Mental State Examination and the Modified Blessed Test. Arch Neurol 1987;44:924-927.

- 35 Weyer G, Erzigkeit H, Kanowski S, Ihl R, Hadler D: Alzheimer's disease assessment scale: reliability and validity in a multicenter clinical trial. Int Psychogeriatr 1997;9:123138.

36 de Zubicaray G, McMahon K, Eastburn M, Pringle AJ, Lorenz L, Humphreys MS: Support for an auto-associative model of spoken cued recall: evidence from fMRI. Neuropsychologia 2007;45:824-835.

37 Uncapher MR, Wagner AD: Posterior parietal cortex and episodic encoding: Insights from fMRI subsequent memory effects and dual-attention theory. Neurobiol Learn Mem 2009;91:139-154.

38 Daselaar SM, Prince SE, Cabeza R: When less means more: deactivations during encoding that predict subsequent memory. Neuroimage 2004;23:921-927.

39 Vannini P, O’Brien J, O’Keefe K, Pihlajamaki M, Laviolette P, Sperling RA: What goes down must come up: role of the posteromedial cortices in encoding and retrieval. Cereb Cortex 2011;21:22-34.
40 Wagner AD, Shannon BJ, Kahn I, Buckner RL: Parietal lobe contributions to episodic memory retrieval. Trends Cogn Sci 2005;9: 445-453.

41 Nyberg L: Perceptual priming and extrastriate cortex: Consensus and controversy. Hum Brain Mapp 2000;10:195-196.

-42 Naghavi HR, Nyberg L: Common fronto-parietal activity in attention, memory, and consciousness: shared demands on integration? Conscious Cogn 2005; 14:390-425.

-43 Buckner RL, Snyder AZ, Shannon BJ, LaRossa G, Sachs R, Fotenos AF, Sheline YI, Klunk WE, Mathis CA, Morris JC, Mintun MA: Molecular, structural, and functional characterization of Alzheimer's disease: evidence for a relationship between default activity, amyloid, and memory. J Neurosci 2005;25: 7709-7717.

44 Buckner RL, Vincent JL: Unrest at rest: default activity and spontaneous network correlations. Neuroimage 2007;37:1091-1096; discussion 1097-1099.

-45 Greicius MD, Krasnow B, Reiss AL, Menon V: Functional connectivity in the resting brain: a network analysis of the default mode hypothesis. Proc Natl Acad Sci USA 2003; 100:253-258

-46 Greicius MD, Srivastava G, Reiss AL, Menon $\mathrm{V}$ : Default-mode network activity distinguishes Alzheimer's disease from healthy aging: evidence from functional MRI. Proc Natl Acad Sci USA 2004;101:4637-4642.

47 Vincent JL, Snyder AZ, Fox MD, Shannon BJ, Andrews JR, Raichle ME, Buckner RL: Coherent spontaneous activity identifies a hippocampal-parietal memory network. J Neurophysiol 2006;96:3517-3531.

48 Raichle ME, MacLeod AM, Snyder AZ, Powers WJ, Gusnard DA, Shulman GL: A default mode of brain function. Proc Natl Acad Sci USA 2001;98:676-682.

49 Sorg C, Riedl V, Muhlau M, Calhoun VD, Eichele T, Laer L, Drzezga A, Forstl H, Kurz A, Zimmer C, Wohlschlager AM: Selective changes of resting-state networks in individuals at risk for Alzheimer's disease. Proc Natl Acad Sci USA 2007;104:18760-18765.

50 Cavanna AE, Trimble MR: The precuneus: a review of its functional anatomy and behavioural correlates. Brain 2006;129:564-583.

51 Miller SL, Celone K, DePeau K, Diamond E, Dickerson BC, Rentz D, Pihlajamaki M, Sperling RA: Age-related memory impairment associated with loss of parietal deactivation but preserved hippocampal activation. Proc Natl Acad Sci USA 2008;105:21812186

52 Sperling RA, Laviolette PS, O'Keefe K, O'Brien J, Rentz DM, Pihlajamaki M, Marshall G, Hyman BT, Selkoe DJ, Hedden T, Buckner RL, Becker JA, Johnson KA: Amyloid deposition is associated with impaired default network function in older persons without dementia. Neuron 2009;63:178-188. 
53 Yonelinas AP, Otten LJ, Shaw KN, Rugg MD: Separating the brain regions involved in recollection and familiarity in recognition memory. J Neurosci 2005;25:3002-3008.

54 Damasio AR, Damasio H: The anatomic basis of pure alexia. Neurology 1983;33:15731583.

55 Buckner RL, Sepulcre J, Talukdar T, Krienen FM, Liu H, Hedden T, Andrews-Hanna JR, Sperling RA, Johnson KA: Cortical hubs revealed by intrinsic functional connectivity: mapping, assessment of stability, and relation to Alzheimer's disease. J Neurosci 2009; 29:1860-1873.

56 Mesulam M: Neurocognitive networks and selectively distributed processing. Rev Neurol (Paris) 1994;150:564-569.

57 Sporns O, Honey CJ, Kotter R: Identification and classification of hubs in brain networks. PLoS One 2007;2:e1049.

58 Kayser AS, Erickson DT, Buchsbaum BR, D'Esposito M: Neural representations of relevant and irrelevant features in perceptual decision making. J Neurosci 2011;30:1577815789.
59 Lopez MN, Charter RA, Mostafavi B, Nibut LP, Smith WE: Psychometric properties of the Folstein Mini-Mental State Examination. Assessment 2005;12:137-144.

60 Carter SF, Caine D, Burns A, Herholz K, Lambon Ralph MA: Staging of the cognitive decline in Alzheimer's disease: insights from a detailed neuropsychological investigation of mild cognitive impairment and mild Alzheimer's disease. Int J Geriatr Psychiatry 2011. DOI $10.1002 / \mathrm{gps} .2738$

61 Humbert IA, McLaren DG, Malandraki G, Johnson SC, Robbins J: Swallowing intentional off-state in aging and Alzheimer's disease: Preliminary study. J Alzheimers Dis 2011;26347-354.

62 Humbert IA, McLaren DG, Kosmatka K Fitzgerald M, Johnson S, Porcaro E, Kays S, Umoh EO, Robbins J: Early deficits in cortical control of swallowing in Alzheimer's disease. J Alzheimers Dis 2010;19:1185-1197.

63 Nelissen N, Dupont P, Vandenbulcke M, Tousseyn T, Peeters R, Vandenberghe $\mathrm{R}$ : Right hemisphere recruitment during language processing in frontotemporal lobar degeneration and Alzheimer's disease. J Mol Neurosci 2011;45:637-647.
64 Atri A, Shaughnessy LW, Locascio JJ, Growdon JH: Long-term course and effectiveness of combination therapy in Alzheimer disease. Alzheimer Dis Assoc Disord 2008;22. 209-221.

65 Porsteinsson AP, Grossberg GT, Mintzer J, Olin JT: Memantine treatment in patients with mild to moderate Alzheimer's disease already receiving a cholinesterase inhibitor: a randomized, double-blind, placebo-controlled trial. Curr Alzheimer Res 2008;5:8389.

66 Van Essen DC: A population-average, landmark- and surface-based (PALS) atlas of human cerebral cortex. Neuroimage 2005;28: 635-662.

67 Van Essen DC, Drury HA, Dickson J, Harwell J, Hanlon D, Anderson CH: An integrated software suite for surface-based analyses of cerebral cortex. J Am Med Inform Assoc 2001;8:443-459. 